\title{
O COSMOPOLITISMO DE CÓCORAS
}

\begin{abstract}
JOSÉ LUÍSFIORI*
Lembro sempre a amargura, o desespero com que pusemos os olhos rebrilhantes de orgulho naquele carro fatal, atulhado de caboclos, que a mão de providência meteu em préstito por ocasião das festas do Congresso Pan-Americano. Abríamos a nossa casa para convidados da mais rara distinção e de todas as nações da América. Recebíamos até norte-americanos!... No melhor da festa, como se tivessem caído do céu ou subido do inferno eis os selvagens medonhos, de incultas cabeleiras metidas até os ombros, metidos com gente bem penteada, estragando a fidalguia das homenagens, desmoralizando-nos perante 0 estrangeiro, destruindo com seu exotismo o nosso chiquismo. A Semana, Jornal do Comércio, Rio de Janeiro, 30/3/1908 (Apud. $\mathrm{N}$ icolau Sevecenko, Literatura como missão).
\end{abstract}

RESU M 0: Este texto trata a respeito dos distintos referenciais que permitiram a compreensão dos diagnósticos sobre os determinantes da crise brasileira dos anos 80 e o fracasso da estratégia desenvolvimentista que vigia até 0 momento em que o Estado brasileiro, que abdicou de muitos dos papéis que lhe couberam nas décadas anteriores, abriu mão do espaço que detinha como condutor do desenvolvimento do país. Com relação à década de 90 , deve-se ressaltar que este Estado tem levado às suas últimas conseqüências um projeto de inserção internacional edetransnacionalização radical do controle dos nossos centros de decisão e de nossas estruturas econômicas, com o apoio de uma aliança de poder estabelecida por nossas elites econômicas e políticas - que muitas vezes atuam como defensoras e porta-vozes de fortes interesses internacionais -, com base num diagnóstico prévio, fortemente influenciado por considerações de cunho ideológico.

Palavraschave: Estado-nação; G lobalização; C entro/periferia; C onsenso de Washington; Neoliberalismo; Cosmopolitismo.

* D outor em Ciência Política pela Universidade de São Paulo (USP) e Professor Titular de Economia Política Internacional da Universidade Federal do Rio de Janeiro (UFRJ) e da Universidade Estadual do Rio de Janeiro (UERJ). E-mail: jIfiori@globo.com 


\section{0 queé de $D$ eus e o que édo homem}

Foi costume divergir sobre o futuro brasileiro, na década de 1980, a partir de diagnósticos diferentes sobre a natureza da crise e a falta de rumo do Estado e da estratégia desenvolvimentista, e, na década de 1990, a partir da discussão em torno da origem, natureza e objetivos dos ajustes e reformas implementadas pelos três governos eleitos no período. Era 0 tempo em que se debatia o alinhamento ou não do governo brasileiro com o Consenso de Washington e com as políticas de corte neoliberal. $\mathrm{N}$ a entrada do novo século, esta é uma discussão completamente ultrapassada. D epois do artigo-depoimento de Joseph Stiglitz - membro da assessoria econômica da Presidência norte-americana e ex-economista chefe do BIRD (publicado pela FSP em 15/4/2000) - sobre a crise financeira iniciada em 1997, ficou absolutamente clara a forma em que o Tesouro americano e o FM I operam, urbe et orbi, as mesmas políticas e reformas econômicas impostas aos países devedores ou que tenham passado por crises financeiras ou de balanço de pagamentos. E depois da assinatura, em 1999, do Acordo com o FM I que permitiu ao governo brasileiro enfrentar a crise terminal do Plano Real com um empréstimo internacional, ninguém mais discute se 0 país ainda tem uma política própria, nem tampouco qual seja a natureza e os objetivos das decisões tomadas com vista ao cumprimento dos objetivos definidos pelo próprio Acordo. O s que ainda desconheciam agora já sabem como atuam juntos - Tesouro americano e o FM I na tutela de países administrados ou não por pequenos burocratas locais ou representantes diretos dos organismos multilaterais.

D e qualquer maneira, o importante é que se tenha claro que esta tutela não foi uma mera imposição externa e, antes do Acordo de 1999, aceitá-la foi uma opção interna de nossas elites econômicas e políticas comandadas, hoje, por uma aliança bem sucedida entre o que se poderia chamar de 'cosmopolitismo de cócoras' de uma parte da intelectualidade paulista e carioca atrelada às "altas finanças internacionais", e o 'localismo' dos donos do 'sertão' e da 'malandragem' urbana brasileira. Aliança de poder que está levando até às suas últimas conseqüências um projeto de inserção internacional e de transnacionalização radical de nossos centros de decisão e das estruturas econômicas brasileiras, com base num diagnóstico que consideram realista, das tendências do capitalismo contemporâneo. Leis que seriam inapeláveis e incontornáveis para um país situado na periferia da nova ordem global. Realismo subalterno e economicismo vulgar, que permitiu reunir liberais e marxistas num novo bloco 
intelectual de poder, com profundas raízes na academia brasileira. Por isso, nesta nova década, o contraditório sobre o futuro do país passa, agora, por uma discussão desta leitura equivocada das transformações mundiais e de suas conseqüências mais prováveis sobre a economia e a sociedade brasileiras.

\section{0 'novo renascimento'}

0 'tempo longo' do universo em que o Brasil constituiu-se como Estado-nação é o mesmo da modernidade capitalista européia e da expansão imperial dos seus estados territoriais, mas seu futuro imediato, no contexto internacional, ocorrerá dentro de um tempo conjuntural que se inaugurou com o fim da Segunda Guerra M undial, passando por um 'ponto de ruptura' decisivo que começou no fim da década de 1960. Entre 1968 e 1973, ocorreu um verdadeiro 'cluster' de decisões e acontecimentos, cujas conseqüências mais duradouras acabaram mudando a face do sistema capitalista e as coordenadas em que se dará, neste novo século, a disputa entre povos, Estados e nações pelo poder e riqueza mundiais. É o momento em que se somam e multiplicam a escalada dos conflitos sociais nos países centrais; a vitória de várias lutas de libertação nacional, na periferia da 'ordem americana'; e a 'indisciplina' dos capitais privados em fuga na direção do euromercado de dólares, com o questionamento da política internacional norte-americana, por parte de seus principais aliados europeus e asiáticos. Foram estes fatos e a resposta a estes desafios que estão na origem das mudanças responsáveis por esta "segunda grande transformação" da ordem capitalista que se cristalizou nos últimos vinte e cinco anos do século 20. D e forma extremamente simplificada, elas podem ser agrupadas em sete campos ou dimensões fundamentais:

I) A primeira, de natureza geopolítica, passou pela crise e restauração da hegemonia mundial norte-americana, pelo fim da U nião Soviética e da Guerra Fria e a atual reafirmação do Atlântico N orte como epicentro político-militar e econômico do mundo capitalista; II) a segunda ocorreu no campo político-ideológico e suas raízes remontam à crise de "ingovernabilidade democrática" e culmina com a restauração liberal-conservadora que se anuncia nos Estados U nidos, na administração $\mathrm{N}$ ixon, mas só é completamente vitoriosa depois das vitórias eleitorais de M argareth Thatcher e Ronald Reagan, na década de 1980; III) a terceira grande transformação se deu no campo econômico, também na produção, mas, sobretudo, na área monetário-financeira onde se 
concentra o núcleo duro do que veio a se chamar globalização. Suas origens também remontam aos anos 60 e ao início do processo de desregulação financeira que começou com a criação do euromercado de dólares e deu seu segundo passo com o fim do sistema de paridade cambial acordado em Bretton Woods. Sua expansão, contudo, só ocorreu nos anos 80, associada de forma íntima com as políticas iniciadas pelos governos anglo-saxões e que depois se universalizaram, por obra da "desregulação competitiva". Como produto final nasce, nos anos 90, uma finança mundial privada e desregulada por cujas veias circula e se acumula uma riqueza rentista que já está na ordem de 3 a 4 trilhões de dólares por dia. IV) a quarta grande mudança responde pelo nome de 'revolução tecnológica', cujas invenções e descobertas fundamentais ocorreram durante a Segunda Guerra M undial, mas cuja utilização econômica só ocorreu a partir da crise econômica dos anos 70, provocando alterações produtivas e gerenciais que têm permitido aumentos de produtividade e lucratividade, sobretudo depois de 1990, às custas, em grande medida, de uma redução gigantesca dos postos de trabalho; V) a quinta transformação vem ocorrendo no campo do trabalho ou do emprego, onde as políticas deflacionistas e as mudanças tecnológicas provocam uma desaceleração dos investimentos e uma reestruturação produtiva que atingiram pesadamente 0 mundo do trabalho, do ponto de vista do número de empregos, de sua remuneração, da sua organização sindical e dos direitos sociais e trabalhistas; VI) a sexta transformação ocorreu no espaço da periferia capitalista e representou uma mudança radical da estratégia, seguida pelos seus principais estados, desde a Segunda Guerra Mundial, com objetivo de promover seu desenvolvimento econômico. Esta grande mudança de estratégia foi mais um resultado da crise econômica mundial que se alastrou a partir dos países centrais, desde o fim do Sistema de Bretton Woods, e atingiu as principais economias periféricas nos anos 80 . D e forma mais ou menos generalizada, estes países, depois de uma década, aparecem, no final dos anos 90, como um universo relativamente homogêneo do ponto de vista de suas políticas econômicas e de sua forma de inserção desregulada e subordinada às finanças privadas internacionais; VII) uma uniformidade que alimenta a tese corrente de que esteja ocorrendo uma perda universal de soberania dos Estados nacionais. $\mathrm{N}$ a verdade, o número de estados nacionais cresceu nestes últimos vinte e cinco anos, e o que alguns usam como argumento legitimador de sua abdicação do poder nacional foi um aumento da distância entre o poder e a riqueza dos Estados do 'núcleo central' do sistema e os da sua periferia. 
Q uase todos os analistas estão hoje de acordo, com pequenas variações, que estas foram as principais transformações que, neste último quarto de século, alteraram a geopolítica e a geoeconomia do mundo tal como foi organizado depois do fim da Segunda Guerra, sob a égide da competição interestatal entre os Estados U nidos e a União Soviética. As grandes divergências não estão neste ponto, estão na forma pela qual cada um interpreta o movimento mais geral, hierarquizando suas determinações e extraindo diferentes conseqüêencias propositivas. De um lado, alinham-se os liberais e marxistas que subscrevem a interpretação hegemônica e privilegiam os aspectos econômicos desta segunda "grande transformação" do século 20. Para eles, trata-se de uma conseqüência necessária e inapelável das transformações tecnológicas que, somadas à expansão dos mercados, derrubaram as fronteiras territoriais e sucatearam os projetos econômicos nacionais, promovendo uma redução obrigatória e virtuosa da soberania dos Estados. A partir daí, a própria globalização econômica e a força dos mercados promoveriam uma homogeneização progressiva da riqueza e do desenvolvimento, através do livre comércio e da completa liberdade de circulação dos capitais privados, 0 que acabaria conduzindo a humanidade na direção de um governo global, uma paz perpétua e uma "democracia cosmopolita".

D o nosso ponto de vista, esta visão hegemônica tem um forte viés ideológico e no fundo reproduz, no que tem de essencial, a velha utopia liberal que desde 0 século XVIII vem anunciando e propondo, reiteradamente, esta hora final e apoteótica da economia capitalista: um mercado global desvencilhado dos problemas impostos pelos particularismos nacionais e os protecionismos estatais. 0 problema é que esta utopia vem sendo reiteradamente negada pelos caminhos reais da história econômica e política do capitalismo e parece cada vez mais distante do que vem ocorrendo, de fato, nestes últimos vinte e cinco anos de história. Para nós, o fenômeno da globalização econômica é inseparável das transformações políticas e ideológicas e das conseqüências sociais deste período. Ela não é uma imposição tecnológica, nem, tampouco, apenas um fenômeno puramente econômico, envolvendo novas formas de dominação social e política que resultaram de conflitos, estratégias e imposição vitoriosa de determinados interesses, tanto no plano internacional quanto no espaço interno dos Estados nacionais. N esse sentido, nossa visão da ruptura e das transformações que se desdobram a partir dos anos 70 corresponde a uma visão ou teoria mais ampla sobre a dinâmica do capitalismo histórico e sobre as suas permanências e regularidades que atravessam os pontos de ruptura, mantendo-se vigentes, na expressão 
de Fernand Braudel, como "leis estruturais e de longo prazo do sistema". Estruturas e regularidades que incluem um movimento simultâneo e interrelacionado de acumulação de poder e riqueza, alavancado a um só tempo pela competição interestatal e pelas relações de dominação entre os poderes dominantes e os grupos sociais e países subordinados. D esde a constituição do capitalismo como um sistema econômico global e nacional a um só tempo e da constituição dos Estados territoriais, houve certas regras constantes de relacionamento entre os Estados e destes com seus capitais privados. Considera-se, normalmente, que o Capital sempre teve uma vocação à globalidade que seria permanentemente contida pelos poderes territoriais ou pela 'mesquinharia' dos estados. M as esta não é uma visão fiel aos fatos e à história. D esde suas origens, os Estados territoriais e os capitais demonstraram a mesma vocação compulsiva e competitiva ao império e à globalidade. Foi assim na primeira onda colonial européia - entre 1500 e a derrota francesa na disputa com a Inglaterra pelo domínio comercial da Índia, na metade do século XVIII - como também na segunda grande onda colonial inaugurada, uma vez mais, na Índia, na metade do século XIX.

$N$ esse sentido, o nosso entendimento da grande transformação deste final de século não apenas supõe uma visão estrutural da modernidade capitalista diferente do economicismo, seja liberal ou marxista, como tem uma visão igualmente distinta do ciclo ou conjuntura em que se inscrevem estas mudanças. Para nós, elas são produto de uma estratégia política e financeira explícita que se impôs ao mundo, desde 0 início dos anos 80, a partir do seu eixo anglo-saxão, mas cujas raízes remontam, muito mais atrás, às lutas de interesse e às discussões que redesenharam o cenário mundial depois da Segunda Guerra.

\section{Conspiração ou estratégia imperial?}

$\mathrm{N}$ ão há quem não conheça o discurso que fez W inston Churchill, no dia 5 de março de 1946, nos Estados U nidos, quando formulou as bases ideológicas e estratégicas da Guerra Fria. Ele já não era mais primeiro-ministro da Inglaterra, mas mantinha a autoridade moral e política que lhe permitiu enterrar o espírito de Yalta e o projeto mundial de Roosevelt, propondo uma nova estratégia de poder que foi consagrada pela D outrina Truman e levou à bipolarização ideológica e militar do mundo que se prolongou até 1991 . M as não são muitos os que prestaram atenção a uma outra passagem menos conhecida do mesmo discurso de Churchill, onde ele propunha uma aliança preferencial, a única capaz 
de reorganizar e pacificar o mundo, ao afirmar que "nem a prevenção da guerra nem o crescimento contínuo da organização mundial serão conquistados sem a organização fraterna dos povos da língua inglesa". U ma semana depois, no dia 15 de março, Stalin respondeu ao ex-primeiroministro inglês dizendo, numa entrevista ao Pravda, que "Churchill e seus amigos na Inglaterra e Estados Unidos apresentaram um ultimato às nações que não falam inglês: aceitem voluntariamente o nosso domínio e tudo estará bem; de outro modo a guerra será inevitável".

$\mathrm{H}$ oje, olhando retrospectivamente, não é difícil perceber que Stalin captou o essencial, o projeto de mais longo prazo que Churchill propunha aos americanos, escudado no sucesso da primeira bomba atômica lançada pelos Estados U nidos sobre H iroshima, no dia 6 de agosto de 1945. De fato, tratava-se de um ultimato, análogo ao que alguns governantes ouviram da parte de Bill Clinton e Tony Blair na reunião dos cinco chefes de Estado, que se realizou em Florença, em novembro de 1999, só que agora numa outra linguagem e escudado no poder estrutural das finanças anglo-saxônicas: "em caso de desobediência não haverá guerra, mas o castigo dos mercados será inevitável".

0 paradoxal nesta história é que foi a escalada belicosa da Guerra Fria, iniciada por Churchill e Truman, que bloqueou os interesses da banca e das finanças, na década de 1940. E, ao contrário, foi a escalada dos interesses financeiros anglo-saxões que deu a contribuição decisiva à vitória na Segunda G uerra Fria, iniciada por Reagan eT hatcher, na década de 1980. Tudo isto pode parecer muito confuso, mas na verdade trata-se do fio condutor capaz de explicar a forma e a extensão da vitória do poder das armas e das finanças anglo-saxônicas, depois da queda do M uro de Berlim.

Entre 1942 e 1944, nas discussões que culminaram nos Acordos de Bretton Woods, acabaram prevalecendo algumas das idéias centrais das representações inglesa e norte-americana, lideradas por Lord K eynes e $\mathrm{H}$ arry D exter White, respaldadas, em última instância, pelo poder e pelo projeto global do presidente Roosevelt. N estas discussões, entretanto, não estiveram ausentes os representantes dos bancos e das finanças em geral e sua defesa intransigente, não apenas do livre-comércio, mas também da livre circulação de capitais e da plena conversibilidade imediata de todas as moedas, num retorno às regras que vigoraram entre $1870 \mathrm{e}$ 1930, sob hegemonia inconteste das "altas finanças" inglesas. M as foram derrotadas transitoriamente pela tese de Keynes de que esta liberalização imediata impediria o funcionamento eficaz de políticas econômicas 
capazes de atender objetivos nacionais, como vieram a ser a construção do welfare state, nos países europeus, ou o desenvolvimentismo na periferia latino-americana. Apesar disso, $\mathrm{H}$ enry Truman, depois de morte de Roosevelt, em abril de 1945, substituiu o Secretário do Tesouro H enry M orgenthau, que sustentara as posições de W hite e Keynes e devolveu de fato o poder aos bancos, entre 1945 e 1947, quando houve uma tentativa de acelerar a liberalização dos mercados de capitais e a completa conversibilidade das moedas, responsáveis pela crise cambial européia de 1947, provocada pela escassez de dólares, que haviam emigrado em direção ao mercado norte-americano. Foi esta crise que, somada à vitória dos 'falcões' no campo da política externa americana, trouxe de volta as teses keynesianas e permitiu a implementação do Plano M arshall, como uma resposta imediata e inicial à ameaça eleitoral comunista em vários países europeus. Foi assim que nasceu essa estranha aliança de interesses que sustentou, simultaneamente, a Guerra Fria e as políticas keynesianas dos new dealers americanos e europeus. $M$ as, assim como 0 projeto liberal dos mercados monetários e financeiros auto-regulados não esteve ausente de Bretton Woods, da mesma forma manteve-se ativo na defesa de suas posições e na crítica ao keynesianismo durante toda a chamada era de ouro do capitalismo. É neste sentido que se pode afirmar que o fim da Guerra Fria também foi o fim do último suporte de Bretton Woods. M as, antes disto, os governos de Ronald Reagan e $M$ argareth Tatcher já haviam trocado os sinais da aliança original, conseguindo 0 que parecia improvável: juntar os fal cões da G uerra Fria com os interesses financeiros de Wall Street e da City de Londres, inaugurando a era das políticas monetaristas e desregulacionistas que alavancaram o fenômeno da globalização financeira. É por isto que a globalização não foi uma obra exclusiva dos mercados ou do progresso tecnológico: ela foi impulsionada por uma crença ideológica e nasceu como irmã siamesa de uma estratégia geopolítica que culminou com a queda do M uro de Berlim e a desintegração da U nião Soviética. Stalin só se enganara numa coisa: não foi necessário o recurso à guerra para a vitória da coalizão de forças que trouxe de volta ao poder as mesmas "altas finanças" de que nos fala Karl Polanyi e que dominaram o mundo entre 1870 e 1930.

É nesse sentido, aliás, que muitos falam num retorno, neste final de século, aos trilhos da "civilização liberal" do século 19. M as este aparente retorno às origens liberais do sistema não deve ser confundido com uma simples volta atrás. Sobretudo as relações entre 0 império e 0 atual sistema monetário internacional - "dólar flexível' - são completamente diferentes das relações que a Inglaterra manteve com o sistema 
do padrão-ouro. 0 novo sistema permite aos Estados U nidos, em particular, funcionarem como uma espécie de 'império hidráulico' capaz de sugar riqueza financeira através do manejo de sua moeda, que não obedece a nenhum outro padrão de referência que não seja o próprio poder norte-americano.

Entretanto, o próprio núcleo central do sistema interestatal de gestão política do capitalismo está em processo de reestruturação. Embora seus Estados-membros sejam os mesmos desde a segunda metade do século 19, o mais provável é que nas primeiras décadas do século 21 ele sofra uma profunda transformação com a unificação européia e a entrada da China no grupo das grandes potências. Esta transição deve reativar no médio prazo a lei da complementariedade e competição que move as relações do núcleo central do sistema e desenha as janelas de oportunidades de suas periferias. 0 mais provável é que esta transição seja muito lenta e se dê na forma de uma longa guerra de posições, comerciais e financeiras, como já se pode ver no impasse em que encalhou a Rodada do M ilênio, que deveria haver começado em dezembro de 1999, em Seattle, nos EUA.

Q ual o lugar dos Estados periféricos, como o Brasil, dentro desta ordem em transição? C om toda certeza se manterão na condição de periferia do sistema e, por isso, seguirão condicionados aos seus ciclos. M as também nestes países, depois das reformas liberais, o que se assiste hoje é a uma espécie de retorno ao passado e, de novo, ao século 19. É como se hoje estivessem mais próximos de sua inserção mundial em 1890 do que da posição que al cançaram durante a sua 'fase desenvolvimentista' na segunda metade do século 20 . 0 novo sistema monetário internacional "dólar flexível" funciona para eles com um simulacro do padrão-ouro, submetendo-os novamente, depois de um longo período de relativa autonomia de suas políticas nacionais, às mesmas regras que 0 padrãoouro impôs à periferia, do ponto de vista de suas exigências draconianas de equilíbrio monetário e fiscal com a conseqüente perda de capacidade de auto-definir os seus próprios objetivos nacionais. Por isso, neste final de século, voltaram a estreitar-se os seus caminhos e as suas possibilidades de desenvolvimento. É como se, tal como no final do século 19, Ihes restassem duas alternativas: a que foi seguida com sucesso pelos chamados 'capitalismos tardios', como foi o caso da Alemanha e do Japão, ou o que foi seguido, também com sucesso, pelos domínios ingleses, como Canadá, Austrália e N ova Zelândia. Esses últimos territórios sempre tiveram um estatuto especial dentro do império britânico: não tinham autonomia política ou monetária, mas tinham um governo local. I sso lhes permitiu 
a transformação numa espécie de territórios contínuos ou complementares, com acesso privilegiado aos investimentos britânicos. $\mathrm{H}$ oje já não cabem dúvidas de que a utopia não declarada de alguns governantes latinoamericanos é a de serem salvos pelo império, transformando-se em novos tipos de domínios norte-americanos. U m projeto praticamente impossível, porque os Estados U nidos não querem nem podem sustentá-lo. Em primeiro lugar, porque os domínios ingleses eram complementares com a Inglaterra do ponto de vista econômico, o que não é o caso latinoamericano com relação aos Estados U nidos. Abrir nichos, buscar a complementariedade comercial, pode funcionar para um país do tamanho do Chile, mas não para um país como o Brasil, por exemplo, cuja estrutura produtiva e pauta de exportações é muito mais diversificada, tendo, consequentemente, de enfrentar a competição e as barreiras que protegem os produtores norte-americanos. 0 estatuto dos domínios supunha uma integração positiva e muito estreita entre capitais e poder estatal, não só para ganhar, mas para perder. A Guerra Fria permitiu isso. Hoje, os capitais americanos não têm nenhuma razão geopolítica que justifique apostar em lugares em que eles podem sofrer grandes perdas.

Em síntese, não é fácil encontrar na história outro momento em que a riqueza e o poder mundiais tenham se somado e concentrado de maneira tão gigantesca, como neste final de século. N em há, na modernidade capitalista, outra época em que a distância entre as nações crescesse tão rapidamente como nestes últimos vinte anos. A economia americana cresce há nove anos sem parar; os europeus crescem muito menos e a menos tempo, enquanto o resto do mundo - com exceção da China parece estatelado, ora entrando, ora saindo de mais uma crise. 0 s números e os fatos são cada vez mais transparentes e chocantes, como denunciaram os informes anuais de 1999, da O N U, do Bird, da Unctad e, até mesmo, do FM I. O mesmo, e talvez até em maior escala, é o que se constata na distribuiçãa do poder político e militar mundial, desde a Guerra do Golfo.

$\mathrm{N}$ as finanças como nas armas, o que se assiste neste final de milênio é a vitória de um projeto que articulou o poder político-militar e o capital financeiro dos países anglo-saxões e os projetou sobre o mundo, dando origem a um novo tipo de império, anglo-saxão e quase global.

\section{A triste sina da 'modernização' brasileira}

O Brasil não ocupou uma posição relevante na geopolítica da Guerra Fria, mas durante todo o século 20 manteve um alinhamento quase automático com a política internacional norte-americana, 
mantendo também, durante esse período, a posição de principal sócio econômico dos Estados Unidos na periferia sul-americana. I mmanuell Wallerstein o classifica entre os países que pertenceriam à "semi-periferia" do sistema, zona econômica e política que, por suas dimensões e dinamismo, ocupa, segundo ele, um papel decisivo na "despolarização" da ordem econômica e política internacional. Por isso, durante a Guerra Fria, mesmo sem ser incluído entre os países cujo "desenvolvimento a convite" foi fortemente apoiado pelo governo americano, o Brasil transformou-se no laboratório de uma estratégia associada, pública e privada, de desenvolvimento que contemplava todos os segmentos do capitalismo central. Graças a esta posição especial, foi menos sensível às flutuações econômicas e mudanças de rumo estratégico no ciclo posterior à Segunda Guerra Mundial. No 'período desenvolvimentista', o Brasil foi um dos poucos países subdesenvolvidos que conseguiu percorrer quase todos os passos previstos para o processo de industrialização retardatária, registrando uma das mais elevadas taxas médias de crescimento mundial. Por outro lado, quando ocorreu sua reversão neoliberal tardia, que começa no momento em que acaba a Guerra Fria, ela também seguiu uma velocidade e radicalidade muito grandes e o Brasil acabou cumprindo em poucos anos uma agenda complexa, que em outros países se arrastou por um período de tempo muito mais longo. A despeito da força e velocidade deste segundo movimento de liberalização, entretanto, seus resultados econômicos e sociais foram decepcionantes, de maneira tal que no fim do século 20, depois de 50 anos do clássico debate brasileiro entre Roberto Simonsen e Eugênio Gudin, sobre a vocação econômica do Brasil, a disjuntiva que se recoloca parece ser, uma vez mais, entre desenvolvimentismo e liberalismo, o que nos obriga a relembrar alguns passos decisivos desta trajetória.

Logo depois da inflexão da política externa norte-americana, em 1947, e, sobretudo, depois da vitória da Revolução Chinesa e da Guerra da Coréia, o 'desenvolvimentismo' transformou-se na resposta capitalista - tolerada pelos liberais - ao projeto socialista para os países subdesenvolvidos. Q uase se poderia dizer, parafraseando John W illiamson al gumas décadas depois, que foi ali que se constituiu o primeiro $C$ onsenso de Washington, e ele era desenvolvimentista, apesar de que a ideologia da "estabilização" do Fundo M onetário Internacional já fosse inquestionável.

Se olharmos esta mesma inflexão a partir do Brasil, perceberemos que o desenvolvimentismo brasileiro também nasceu de forma pragmática e foi capaz de aglutinar quase todos os segmentos das classes dominantes 
e suas elites. N ormalmente, e quase naturalmente, são os setores mais dinâmicos, ou aqueles representados pelos setores industriais de ponta, que são colocados sob a luz dos refletores dos estudos de sociólogos e politólogos. No caso brasileiro, essa elite se concentrou em São Paulo em torno do complexo metal-mecânico que então surgia, tendo à frente a indústria automobilística. Essa era a fração mais "moderna" do capitalismo brasileiro e nasce associada ao capital multinacional. Entretanto, outras frações não menos importantes, mas talvez menos 'modernas' do ponto de vista econômico e político, também encontraram o seu espaço dentro da 'coalizão desenvolvimentista'. De fato, naquele período, o desenvolvimento não foi só "intensivo" e concentrado em certos setores e espaços geográficos. Pelo contrário, veio acompanhado da expansão permanente das fronteiras agrícola e urbana, o que permitiu amplas possibilidades de ganhos patrimoniais. 0 próprio sistema de intermediação financeira, que acompanhou o crescimento da economia real, manteve-se nas mão dos capital nacional. Por outro lado, foi esse mesmo dinamismo e a permanente mobilidade da fronteira de ocupação capitalista do país que deram ao modelo uma enorme capacidade de amortecimento das tensões presentes, num processo que foi ao mesmo tempo desigual e excludente.

A extensão da presença do Estado nesta estratégia de desenvolvimento criou a falsa idéia de um Estado forte ou 'prussiano' que nunca existiu no Brasil. $\mathrm{N}$ a verdade, o que ocorreu foi o oposto: o Estado foi forte toda vez que se enfrentou com os interesses populares, mas foi sempre frágil quando teve que enfrentar e arbitrar os interesses heterogêneos do pacto em que se sustentou até a década de 1980, particularmente quando se tratava de interesses internacionais. Enquanto as condições externas foram favoráveis e todos os setores puderam ganhar "fugindo para frente", conseguiu-se uma aliança sólida e permanente dos interesses particulares das regiões e dos grupos econômicos. N o entanto, à medida que ficava claro que essa fase de ouro do capitalismo mundial e, por conseqüência, das condições para o nosso crescimento estavam se alterando drasticamente, as fraturas no bloco dominante ficaram cada vez mais visíveis. 0 mesmo se constatando em outros países da América Latina, onde, pouco a pouco, com pequenas defasagens a partir de 1973, vai sendo revertida a hegemonia do pensamento desenvolvimentista do pós-guerra.

0 golpe de misericórdia, entretanto, veio com o choque externo da subida das taxas de juros internacionais e do preço do petróleo, junto com a queda dos preços das commodities e a nossa exclusão do mercado financeiro internacional, após a moratória do M éxico. Foram esses choques 
que provocaram um efeito em cadeia sobre o câmbio, a inflação, o endividamento interno, o crescimento econômico e finalmente a falência estatal. A causa principal da crise foi o corte do acesso ao financiamento externo, decisivo para uma economia como a brasileira, que já era, desde os anos 60, altamente internacionalizada e globalizada.

O bviamente que 0 marco mais importante para a reversão total desse quadro foi o lançamento do Plano Real de estabilização monetária, em 1994. M as o fato decisivo para o sucesso do programa de estabilização posterior foi o retorno do país ao mercado internacional de capitais, a partir de 1991, viabilizado pela renegociação da dívida e pela liberalização no controle dos fluxos de capital externo. Foi assim que o Brasil chegou à segunda metade dos anos 90 sob a égide de um pensamento e uma política de corte neoliberal, cuja aposta fundamental era no acesso a mais um ciclo de inserção financeira internacional e crescimento acelerado. H oje sabemos que dessa vez a velha história não se repetiu e várias diferenças podem ser reunidas para tentar entender esse momento, bem como as possibilidades que nos esperam no futuro próximo. Passada uma década, generaliza-se a convicção de que o recente ciclo de integração econômico-financeira das elites cosmopolitas parece ter destruído, quase integralmente, a idéia de um desenvolvimento mais autônomo ou nacional.

A inviabilidade deste projeto de nossas elites internacionalizantes - que chamamos de 'dominium' - é que coloca o Brasil frente a um impasse extremamente grave. Suas contradições e inconsistências internas não nos dão a menor esperança de alcançar taxas de crescimento econômico socialmente inclusivas, que poderiam devolver aos nossos governantes a capacidade de governar e, talvez, a legitimidade que perderam frente aos seus cidadãos. $\mathrm{N}$ a verdade, o Brasil também acabou prisioneiro da vitória liberal-conservadora do final da década de 1970 e subscreveu a estratégia dos países centrais, que transformaram a estabilidade monetária no objetivo prioritário dos seus governos e fizeram do monetarismo e do liberalismo a religião oficial da sua política econômica. D esde os anos 90, estas políticas monetárias restritivas, ancoradas no câmbio sobrevalorizado, tiveram um relativo sucesso no combate à inflação, mas desencadearam ao mesmo tempo uma alta das taxas de juros que se transformou em peça essencial da acumulação rentista da riqueza privada e obstáculo intransponível ao seu crescimento. 0 problema é que estas mesmas taxas, permanentemente elevadas, além de induzirem uma desaceleração do crescimento econômico, também provocaram, de maneira simultânea, um desequilíbrio progressivo das 
contas públicas internas. Como as taxas de juros passaram a ser sistematicamente superiores às taxas de inflação e de crescimento, se transformaram em fonte de expansão contínua dos desequilíbrios macroeconômicos que aprisionam e paralisam as políticas públicas. Foi para sair deste impasse que as autoridades brasileiras recorreram, nestes últimos anos, ao endividamento e apostaram no investimento externo abundante, gerando um 'efeito bola de neve' que expande os déficits e as dívidas e pode chegar a ter um custo insustentável para gerar as divisas indispensáveis para pagar as contas. U ma situação, portanto, em que há excesso de liquidez, mas não há solvência, porque o modelo não só não cresce como, tampouco, consegue aumentar suas exportações. Por isto, se a alta das taxas de juros, independente de objetivos deflacionários, continua obedecendo à lógica de atrair capitais externos. Já faz tempo que ela se transformou em peça essencial do novo modo de acumulação da riqueza privada e do novo regime caracterizado por ciclos curtos de baixo crescimento, seguidos de recessões periódicas. E o que se pode prever é um aumento contínuo destes desequilíbrios, sobretudo quando se tem claro que as altas taxas de juros têm sido acompanhadas de um aumento da dívida financeira, responsável por uma insuficiência fiscal crônica, independente do tamanho da receita ou dos superávits primários que possam ser logrados conjunturalmente. N este quadro, a perspectiva é de que os deficits cresçam na forma de uma "bola de neve", modificando a divisão da renda, continuamente, em favor dos rendimentos financeiros, e estrangulando os governos que aceitam e promovem sucessivos e inúteis ajustes orçamentários, provocando uma crescente ingovernabilidade dos estados e de suas instâncias sub-nacionais de poder.

\section{0 cosmopolitismo e a nação}

Em síntese, na entrada do novo milênio, o Brasil não é um país sem rumo. Pelo contrário, segue uma rota cada vez mais transparente, comandado por uma aliança política extensa e heterogênea, arbitrada já não pelos militares, mas - como já dissemos - por um grupo de intelectuais e tecnocratas absolutamente alérgicos à palavra nação. Alguns liberais, outros marxistas, mas todos se sentindo e comportando-se como sacerdotes de uma modernidade liberal e cosmopolita. $\mathrm{N}$ ão se trata de um fenômeno completamente novo. Pelo menos desde o Iluminismo francês e o Idealismo alemão que a intelectualidade tem cumprido um papel decisivo na orientação ou condução das elites e da opinião pública dos Estados nacionais. D esde então, o norte da Europa transformou-se 
no epicentro dinâmico do sistema capitalista e centro difusor do modelo de organização e funcionamento do Estado-nacional moderno. 0 principal sustentáculo do liberal-cosmopolitismo e parâmetro de referência para a definição do que fosse a modernidade. M as já naquela primeira hora do confronto intelectual, $\mathrm{H}$ egel e List argumentaram, de forma conclusiva, que o cosmopolitismo da filosofia iluminista dos 'direitos naturais' e da economia política do 'livre-cambismo' serviam perfeitamente aos interesses das nações e economias mais poderosas, mas eram incapazes de dar conta das condições e objetivos das nações européias mais atrasadas. Foi aí que começou a separação dentro da intel ectualidade, dividida entre os que se espelhavam na modernidade francesa ou inglesa, que se transformou no parâmetro da 'alta cultura' e no relógio da vida econômica e política, e os que puseram seu pensamento a serviço da formação das nacionalidades e da organização dos Estados e das economias na semi-periferia européia do sistema capitalista. D esde então, transformou-se num dado de realidade a tensão permanente que dividiu esta intelectualidade e, progressivamente, do resto de todo sistema, entre 0 seu cosmopolitismo e o seu localismo, entre sua vida urbana e sua mitificação da vida rural, entre suas preocupações sociais e econômicas universalistas e suas lealdades nacionais.

Também no Brasil a sua intelectualidade pesquisou e discutiu, pelo menos desde a segunda metade do século XIX, como transformar a 'identidade nacional' brasileira em fundamento de um projeto de modernização econômica e social. M as foi, sobretudo, nas décadas de 1910 e 1920, com o pensamento conservador e o modernismo que a intelectualidade brasileira se propôs a tarefa de construir uma "comunidade imaginária" em que pudesse sustentar seus projetos de 'organização nacional', ou de revolução democrático-burguesa ou simplesmente de constituição de uma nação cidadã. 0 que tinham de comum era uma preocupação central com 0 atraso brasileiro e com a necessidade de construção de uma nação, às vezes definida na forma contratual francesa ou norte-americana, às vezes numa perspectiva mais próxima da Kulturnation alemã. É conhecida a história da relação de muitos intelectuais com a Revolução de 1930 e o Estado N ovo, e mais tarde na formulação do único projeto político e econômico, na história brasileira, que - independente de desvios - se quis nacional, democrático e popular e que abortou em 1964, transformando-se no principal 'espantalho' dos novos liberais das décadas de 1980 e 1990.

D e uma forma ou outra, durante todo este tempo, permaneceu vivo, ainda que minoritário, o pensamento liberal-internacionalizante 
ou cosmopolita, quase sempre preso às fórmulas mais elementares do liberalismo econômico. N este campo, a grande novidade da história recente foi a convergência ocorrida entre uma ampla vertente marxista da intelectualidade paulista com os defensores do liberalismo, defendido classicamente pelo Estado de São Paulo e a oligarquia paulista. D aí nasceu um novo e poderoso bloco intelectual e político que se propôs levar a frente - e com sucesso até aqui - o velho projeto da oligarquia paulista, de 'modernização' liberal da vida econômica e social brasileira. A convergência entre as novas condições e interesses financeiros internacionais da década de 1990, somada à bem sucedida renegociação da dívida externa brasileira, nos termos do Consenso de Washington, e a existência desta aliança de poder liderada pelo novo bloco intelectual, criaram uma condição única de aproveitamento de mais um ciclo de liquidez internacional, só que agora, ao contrário do que ocorrera desde 1930, para implementar a transnacionalização radical da economia, em vez de uma tradicional 'fuga para frente' de tipo desenvolvimentista.

Seis anos depois, o país, perplexo, percebe que não tem mais governo, porque o governo não tem mais nenhum projeto para o país. Tinha e fez as reformas e privatizações requeridas e hoje se transformou numa agência de gerenciamento macroeconômico do Acordo Internacional que o salvou da falência na crise final do Plano Real e que definiu, por vários anos, o que serão os objetivos e as prioridades da nação brasileira. Já era assim desde antes, mas depois deste Acordo, nossos intelectuais cosmopolitas transformaram todo seu trabalho como governo numa espécie de permanente redação escrita ou oral de boletins de auto-ajuda macroeconômica. E estão completamente convencidos de que o povo brasileiro se satisfaz com a leitura diária e monótona dos movimentos das bolsas e dos números, que ora anunciam a expectativa de um futuro promissor, ora descrevem 0 avanço milimétrico e irrelevante das variáveis econômicas que se transformaram na sua idéia de $\mathrm{N}$ ação.

Dissemos, no início deste artigo, que as políticas do Tesouro Americano/Fundo M onetário Internacional não poderiam avançar se não tivessem encontrado esta receptividade nacional. E o cosmopolitismo liberal de nossos intelectuais não teria viabilidade se não tivesse sido apoiado decididamente por nossas burguesias locais, interessadas apenas na valorização patrimonial e dolarização da sua riqueza. 0 que estes intelectuais nunca perceberam é que seu cosmopolitismo, quando praticado num país periférico como o Brasil, com uma distribuição prévia extremamente perversa da riqueza e da renda, é um cosmopolitismo de cócoras e só poderia ter como resultado a desintegração definitiva de qualquer 
idéia de nação, seja ela de tipo francesa, norteamericana ou alemã. Aos olhos destes homens, fechados nas suas cápsulas e envoltos em relatórios de auto-estímulo, tudo o que os contradiga será sempre sinônimo de populismo ou insurreição. 0 que desqualifica preliminarmente qualquer conflito social e com isso dissolve a própria essência da vida política e da democracia.

$\mathrm{N}$ ão é sem razão, portanto, que toda vez que algum deles sai de sua abóbada é possuido - invariavelmente - do mesmo sentimento de náusea de algumas elites brasileiras que, ao encontrarem-se com seu povo, sempre tiveram a impressão de estarem se encontrado com "selvagens medonhos e com incultas cabeleiras metidas até os ombros". Selvagens e com comportamento "muito pouco civilizado" (FHC, Jornal do Brasil, 21 mar. 2000).

Recebido para publicação em julho de 2001.

\section{COSMOPOLITISM ON ITSKNEES}

ABST RACT : T his paper studies the different set of references that helped understand the diagnostics on what determined the Brazilian crisis in the 80 sand the failure of the developmentist strategy. Such strategy was in force until theBrazilian State, which had already relinquished many of theroles assumed in the past decades, also abandoned its function as a leader of the Brazilian development. As for the $90 \mathrm{~s}$, based on a previous diagnostic strongly influenced by considerations marked by ideologies and backed by a power alliance between the economical and political elite - who have often acted as advocates and spokespeople of strong international interests - , the Brazilan State took to its ultimate consequences a project of international insertion and radical transnationalization of the control over Brazilian decision centers and economical structures.

Key words: N ation-state; Globalization; C enter/suburbs, Washington Consensus; N eoliberalism; cosmopolitism. 